\title{
The Properties of some Antigens of Trypanosoma brucei
}

\author{
By B. WEITZ \\ The Lister Institute of Preventive Medicine, Elstree, Hertfordshire
}

(Received 26 June 1960)

\begin{abstract}
SUMMARY
A soluble trypanosomal antigen occurs in the serum of rats infected with Trypanosoma brucei. This 'exoantigen' is probably not a protein and is electrophoretically a slow-moving component in the serum. The exoantigen which is also present on the surface as an agglutinogen appears to protect the trypanosomes against adverse environment, preserving their infectivity for long periods in vitro. Rats and mice immunized with exoantigen are protected against infection with the homologous strain of $T$. brucei. Rabbits infected chronically with $T$. brucei form antibodies to exoantigen. On disintegration of the trypanosomes, in addition to exoantigen, 'bound' antigens are released. In the natural disease exoantigens induce antibodies which may be concerned with protection against further infection.
\end{abstract}

\section{INTRODUCTIOM}

Immunological investigations of the African trypanosomes have been largely confined to the application of serological testing techniques without the necessary understanding of the relevant immunological mechanisms. The complement-fixation test (Schochaers, Neujean \& Evens, 1953; Rodhain, Valckeg \& van Gidsenhoven, 1941 ; Pantizel, Lafaije \& Duret, 1959; Fromentin, 1959), the cell adhesion phenomenon (Duke \& Wallace, 1930; Wallace \& Wormall, 1931), the agglutination test (Inoki, Kituana, Nakabayasi \& Kurogochi, 1952; Soltys, 1957), the respiratory inhibition test (Desowitz, 1956, 1959 $a$; Thurston,1958) and the precipitin reaction (Gray, 1960) are but some of the manifestations of a complex immunological system. The exploitation of these methods for the diagnosis of trypanosomiasis and for the classification of trypanosomes has led to confusing and contradictory results, probably owing to the multiplicity of antigenic systems involved. The analysis of the antigens of trypanosomes should elucidate some of these problems, and the present study is an attempt to investigate systematically certain aspects of the mechanisms of immunity in trypanosomiasis. A soluble trypanosomal antigen, called 'exoantigen' which plays a significant role in the immunology of trypanosomiasis has already been briefly described (Weitz, 1960). These investigations are described in detail below.

\section{MATERIALS AND METHODS}

Strain used. A monomorphic strain of Trypanosoma brucei (Shinyanga III) was used. It was isolated from cattle in Tanganyika in 1956 and maintained by rapid passage in mice until a method of keeping the living strain in frozen tubes $\left(-70^{\circ}\right)$ was described by Polge \& Soltys (1957). The passage strain used for day-to-day experi- 
ments was renewed at intervals from a frozen stock. After one or two passages in mice no differences were detected between such strains and those which had been passaged in mice for prolonged periods. Blood from mice taken 2 days after infection caused a maximum parasitaemia and death on the 2nd or 3rd day in the mice into which it was injected.

Animals. White mice from a uniform stock and weighing about 12-17 g. were used for infection experiments. Antigens of trypanosomes were obtained from infected white rats weighing about 150-200 g. Antisera were prepared in 300-500 g. rats and in $2-3 \mathrm{~kg}$. New Zealand Red rabbits.

\section{Antigenic materials}

Infected rat serum (IRS) was obtained from rats by section of the axillary artery under ether anaesthesia 3 days after infection with Trypanosoma brucei, the blood being pooled in $250 \mathrm{ml}$. centrifuge bottles. The serum was obtained after the blood had clotted at room temperature and the trypanosomes had been removed by filtration. The IRS was stored at $-10^{\circ}$ and then freeze-dried. Dilute IRS was also obtained when trypanosomes were washed and, after concentration, had properties identical to native infected rat serum.

Normal rat serum (NRS) was obtained from non-infected rats.

Trypanosome homogenates (TH) were made by bleeding 3-day infected rats into c. 5 vol. of Alsever's solution (Fig. 1). The erythrocytes were removed after centrifugation at $1800 \mathrm{rev} . / \mathrm{min}$. for $3 \mathrm{~min}$. and the supernatant containing the trypanosomes was again centrifuged at $2000 \mathrm{rev} . / \mathrm{min}$. for $7 \mathrm{~min}$. A 'medium' M.S.E. centrifuge (Measuring \& Scientific Equipment, London) was used in all experiments. The supernatant fluid (Supernatant I) was removed and the sediment of trypanosomes was mixed with 10 vol. of Alsever's solution and centrifuged for 5-8 min. at $2000 \mathrm{rev} . / \mathrm{min}$. The resulting supernatant fluid (washing I) was removed and the process repeated (washing II). Finally, the sediment of trypanosomes was resuspended in about 1-2 ml. of saline solution and frozen in special tubes at $-10^{\circ}$ for disintegration in a Hughes (1951) press. The trypanosome homogenate was stored at $+4^{\circ}$ or freeze-dried. Supernatant I and washing I were pooled and concentrated by pressure dialysis to the original volume and, as noted above, used as IRS.

\section{Antisera}

Anti-IRS serum. Rats were injected intramuscularly in the hind legs with a series of 10 weekly doses of $0.5 \mathrm{ml}$. of IRS mixed in equal volumes with $10 \%$ potash alum solution ( $\mathrm{pH} 6 \cdot 8$ ) and bled by cardiac puncture 7 days after the last dose. The rats were given a further dose of IRS and bled 7-10 days later, the procedure then being repeated; although some rats died after heart puncture, the majority were bled 5 to 10 times at intervals of about 10 days. The sera from the bleedings of all the rats at the same stage of immunization were pooled and kept at $-10^{\circ}$ or freeze-dried.

Anti-trypanosome homogenate rat serum (Anti-TH rat serum) was similarly prepared, the rats being inoculated with $0.5 \mathrm{ml}$. of mixtures of 2 vol. of TH and 1 vol. of $10 \%(w / v)$ potash alum solution.

Anti-trypanosome rabbit serum was obtained from rabbits infected by a single 
dose of living trypanosomes derived from infected rat blood. Twice washed trypanosomes were suspended in Alsever's solution in a concentration of $5 \times 10^{5} /$ dose of $0.25 \mathrm{ml}$. Injections by the intravenous, subcutaneous or intracutaneous routes gave similar results. The serum was stored at $-10^{\circ}$ or freeze-dried.

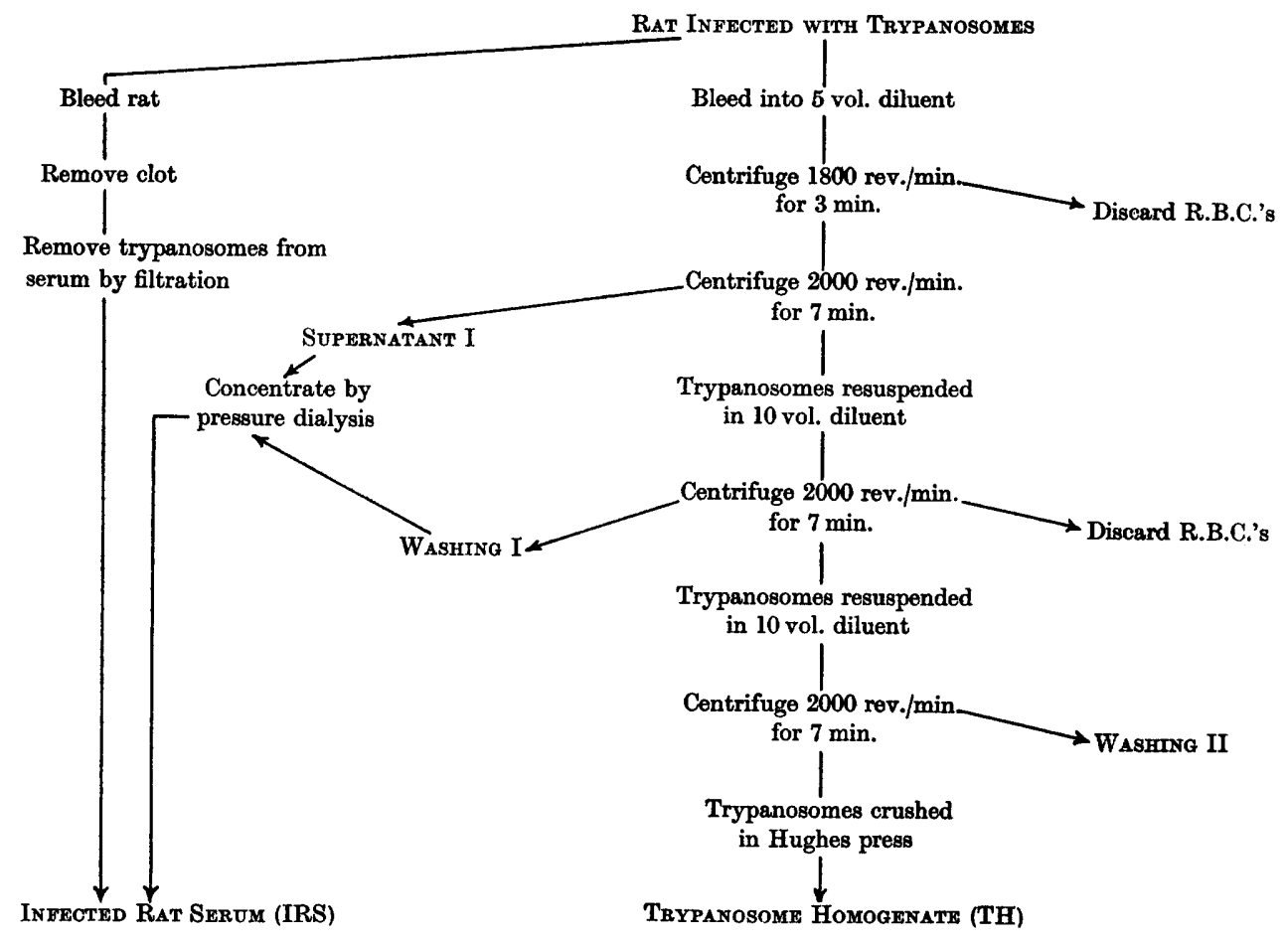

Fig. 1. Procedures in the preparation of infected rat serum and trypanosome homogenate.

\section{Methods of testing}

Mouse-infection experiments. Mice were usually infected with $0.25 \mathrm{ml}$. of suspensions of living trypanosomes by intraperitoneal injection; they were inspected twice daily and deaths recorded.

Agglutination tests. The agglutination test described by Soltys (1957) was done on slides examined microscopically under the $\frac{2}{3}$ in. objective, by mixing one drop of antiserum or control fluid with one drop of trypanosome suspensions derived from infected mice or rats bled into Alsever's solution containing $10 \%$ horse serum.

Gel diffusion tests. Carried out at room temperature by the Ouchterlony method in $1.2 \%$ agar in normal saline containing $1 / 10,000$ thiomersalate.

Electrophoresis and immuno-electrophoresis. Electrophoretic analysis was made in starch gels using phosphate buffer (pH 7·7) according to Smithies (1955) in an electrophoresis tank as described by Kohn (1959). Up to six different samples were analysed in gels measuring $15 \mathrm{~cm} . \times 10 \mathrm{~cm}$. by inserting a piece of filter paper soaked in the sample and passing a current of $150 \mathrm{~V}$ at $35 \mathrm{mAmps}$ for $5 \frac{1}{2} \mathrm{hr}$. The starch gel was sliced in the horizontal plane, the inner surface of one portion being stained 
with naphthalene-black and decolorized in acetic acid + methanol + dist. water mixture $(1+1+1)$.

For immuno-electrophoretic tests starch gels were divided into individual strips by cutting along both edges of each sample and slicing them horizontally. One portion was stained, while the matching slice was laid on a sheet of plate glass and $1.2 \%$ molten agar was poured around the strip to the same thickness. When the agar had solidified, channels were cut out in the agar along the sides of the embedded starch strips and antiserum was poured in these channels. The plate was kept in a moist chamber to allow diffusion of the reagents. On completion of the reaction, the stained portion of the starch gel was laid over the embedded portion and the reacting zones were matched with the stained bands of the electrophorized samples. Alternatively, photographs of the stained strips were superimposed on photographs of the immuno-gel.

\section{RESULTS}

\section{The presence of exoantigen in the serum of infected rats}

Soluble trypanosome antigen ('exoantigen') in the serum of rats infected with Trypanosoma brucei was identified by precipitin tests with anti-IRS serum. IRS antisera, prepared in rabbits also precipitated with normal rat serum (NRS) but after absorption with NRS reacted only with IRS. To avoid using absorbed antisera, entailing difficulties due to excess of the absorbing antigen, rats were immunized with IRS, yielding antisera reacting with rat serum containing exoantigen but not with normal rat proteins. In agar gel anti-IRS rat serum gave a single line of precipitation with IRS and none with NRS. In constant antibody precipitin ring tests, the highest dilution at which IRS precipitated with anti-IRS rat serum indicated the amount of exoantigen in the samples. Various anti-IRS sera reacted at dilutions of $1 / 370$ to $1 / 1280$ of an average preparation of IRS. Comparisons of the titres of IRS obtained from rats at various times after infection suggest that the maximum amount of exoantigen was present in the serum soon before death.

The electrophoresis of NRS and IRS on starch gels stained with naphthalene black were qualitatively identical. Immuno-electrophoresis of these materials with anti-IRS rat serum showed that exoantigen in IRS was a slow moving component and just behind the serum $\gamma$-globulin component. No reaction occurred with the electrophorized NRS (Fig. 2). As exoantigen failed to stain with naphthalene black it is thought unlikely to be protein.

\section{Some biological characters of exoantigen}

It is the usual practice to infect animals with trypanosomes by the injection of infected whole blood, perhaps diluted in suitable fluid for convenience. However, when suspensions of such trypanosomes were washed before injection into mice, the infectivity was greatly reduced. The following experiments show that loss of infectivity was prevented by addition of exoantigen contained in IRS.

Living trypanosomes were obtained from infected mice bled into Alsever's solution. The erythrocytes were removed by centrifugation and the supernatant containing most of the organisms was centrifuged in conical tubes at $2000 \mathrm{rev} . / \mathrm{min}$. for $8 \mathrm{~min}$. After removing the clear supernatant fluid, the sediment of trypanosomes was resuspended in $10 \mathrm{vol}$. of Alsever's solution and again centrifuged. 
From the last sediment, suspensions of trypanosomes were made in Alsever's solution to contain 200, 20 and 2 million organisms per ml.. These were added in equal volumes to each of four dilutions of $1 / 2,1 / 10,1 / 20$, and $1 / 40$ of a five times concen-

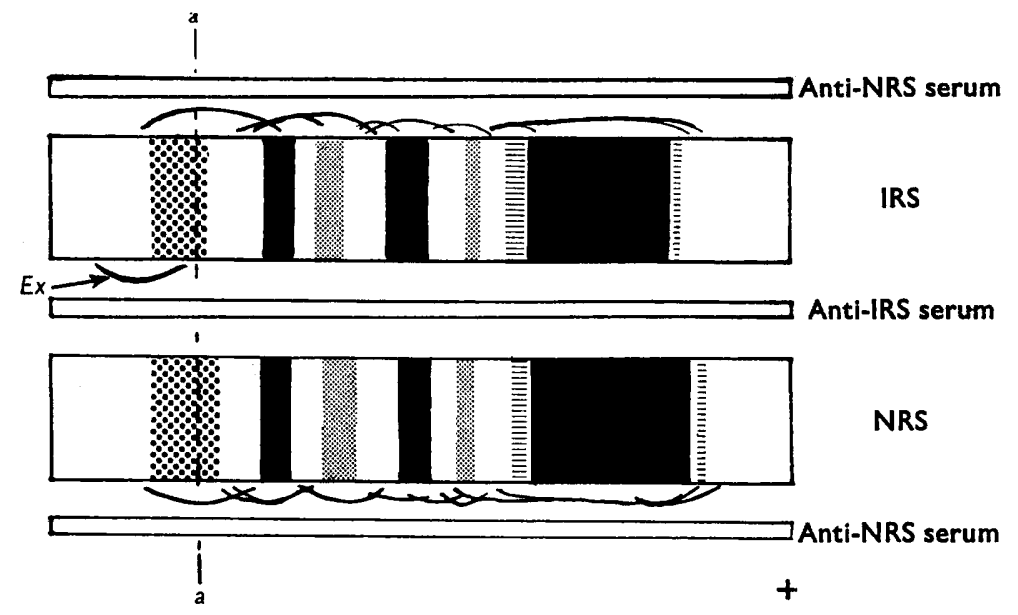

Fig. 2. Electrophoresis of infected rat serum and normal rat serum in starch gels and agar diffusion against antisera to normal and infected rat serum. $a$, a line of insertion of samples; $E x$, line of reaction due to exoantigen.

Table 1. Time to death of mice inoculated with graded doses of Trypanosoma brucei

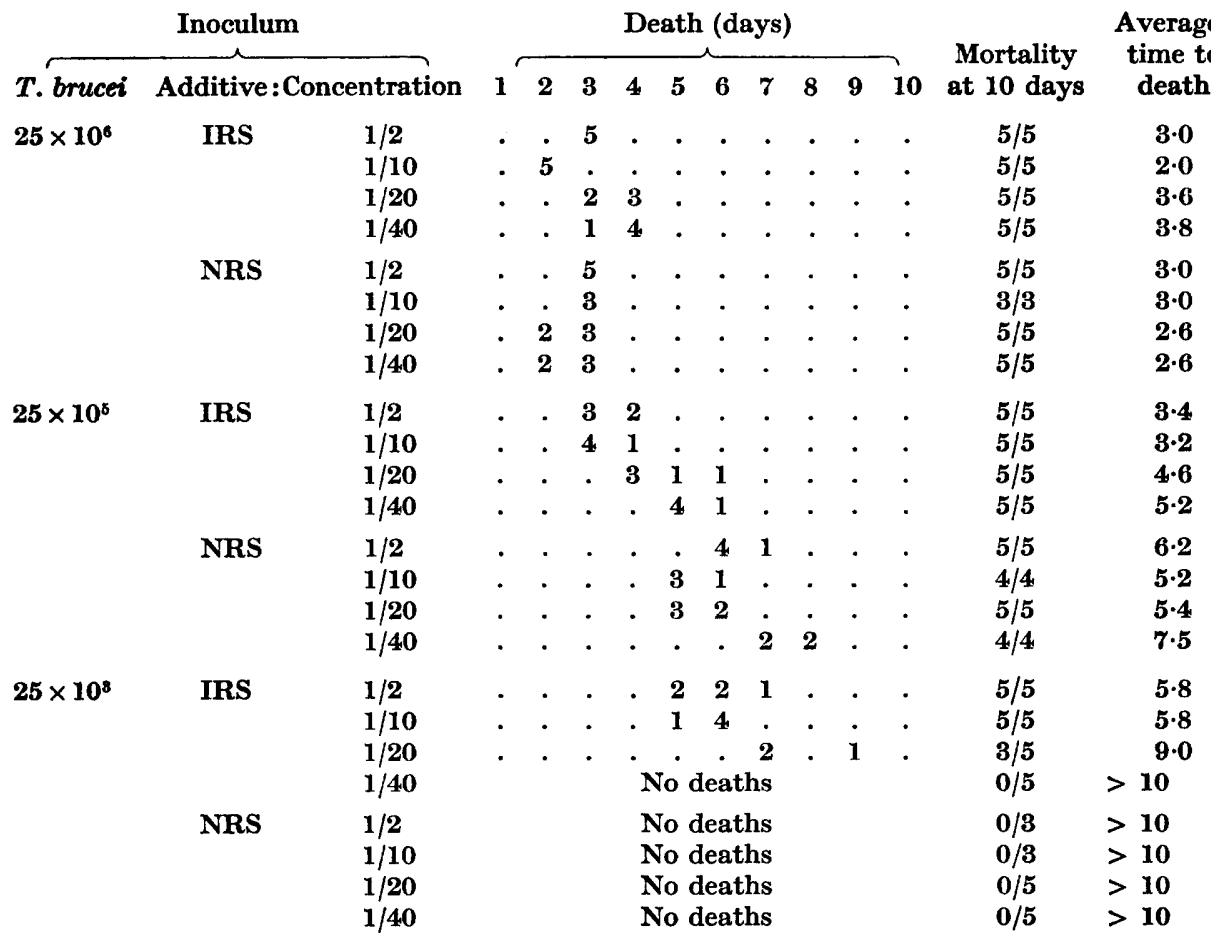

* In calculating the average time to death, survivors on the tenth day were given 11 days life. 
trated IRS and NRS. The mixtures stood at room temperature for $1 \mathrm{hr}$. and $\mathbf{0 \cdot 2 5} \mathbf{~ m l}$. of each mixture was inoculated into each of five normal mice. The numbers of trypanosomes injected into each mouse was thus 25 million, 2.5 million and 250,000 respectively in each group. The mice were observed for 10 days, deaths being recorded daily. The time to death (Table 1) depended on the number of organisms injected and at each dose level was directly proportional to the concentration of IRS or NRS in the inoculum. At all dose levels except the first which had the shortest possible incubation period, the mice which received IRS died earlier than those which received NRS. At the lower dose levels, although the mice which received trypanosomes with NRS survived at 10 days, at the higher concentration of IRS mice died in 5-9 days.

\section{Nature of the increased infectivity of trypanosomes to which exoantigen is added}

This increase in the infectivity of trypanosomes to which IRS was added might be due to agressin-like substances in IRS which enabled the trypanosomes to invade the host more readily. It is more likely that the apparent increase in infectivity was due to the more efficient preservation of trypanosomes in vitro as shown in the

Table 2. Time to death of mice inoculated with 750,000 living Trypanosoma brucei added to infected rat serum (IRS), normal rat serum (NRS) and Alsever's solution for different periods before inoculation

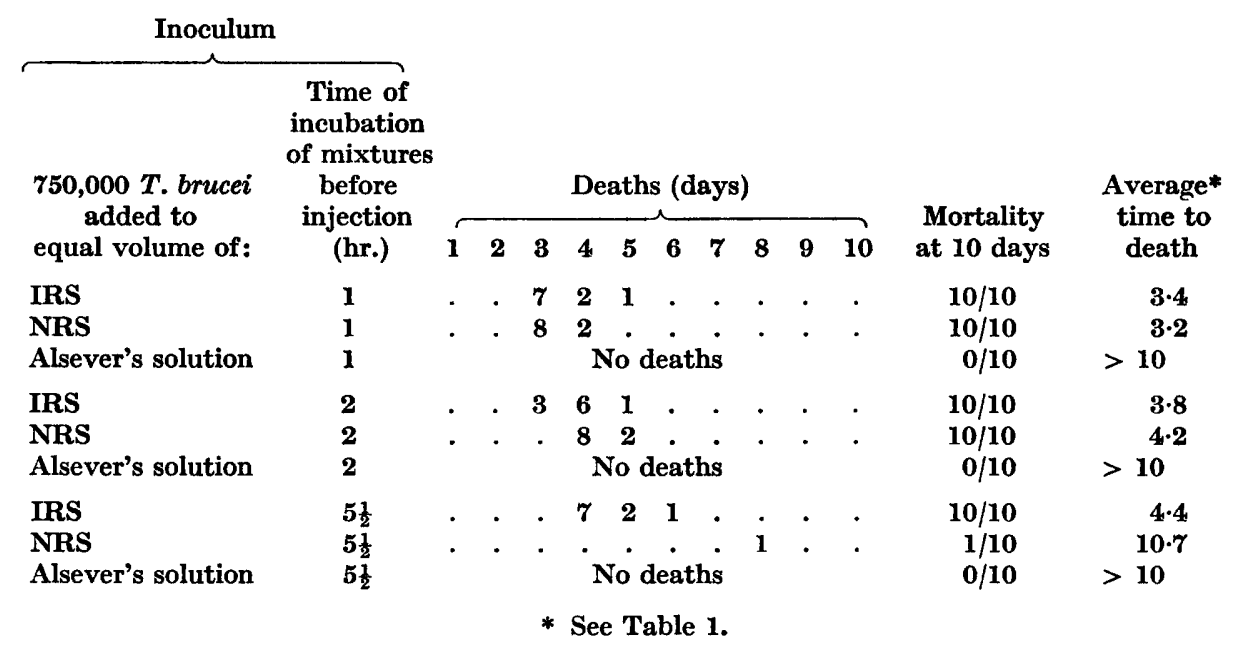

following experiment. Infecting organisms were prepared as in the previous experiment and the trypanosomes were added to equal volumes of undiluted IRS or NRS and plain Alsever's solution respectively. The three suspensions were maintained at room temperature for varying periods of 1,2 and $5 \mathrm{hr}$. before inoculating a dose of $0.2 \mathrm{ml}$. of the mixture into each of 10 mice (see Table 2), so that each mouse received 750,000 organisms. Mice receiving trypanosomes with IRS or NRS incubated for $1 \mathrm{hr}$. died about the 2 nd or 3 rd day, but those receiving the same mixtures incubated for $2 \mathrm{hr}$. died about the 3rd or 4 th day. When the mixtures were incubated for $5 \frac{1}{2} \mathrm{hr}$. before injection, although only one mouse died (8th day) of those 
which had received the trypanosomes with NRS, all the mice which had received $5 \frac{1}{2} \mathrm{hr}$. mixtures of trypanosomes with IRS died about the 3rd or 4th day. No mouse of any group died having received trypanosomes in Alsever's solution alone. Thus, in Alsever's solution, it appears that trypanosomes survive only for short periods while they survive for more prolonged periods in NRS and appreciably longer when suspended in IRS solution containing exoantigen, presumably the responsible component for the more efficient preservation of living trypanosomes in vitro.

\section{Immunological characters of exoantigen}

The experiments described above show the presence of exoantigen contained in IRS and its absence from NRS. The proof that the exoantigen is of trypanosomal origin and not merely an adventitious metabolite of rat serum resulting from infection lies in the following experiments.

The identification of exoantigen. Sera obtained from rabbits chronically infected with Trypanosoma brucei precipitated IRS in gel diffusion or the precipitin ring tests. The lines of precipitation with IRS are identical with the precipitation lines caused by the interaction of IRS and anti-IRS rat serum. No precipitate occurred with NRS. Moreover, rabbit sera absorbed with IRS no longer precipitated IRS. Both antisera, therefore, have identical antibodies. Considering that the rabbits were infected with only a few thousand well-washed trypanosomes it would have been impossible for any contaminating antigen of rat serum to have been injected in the rabbits with the infecting organisms in quantities sufficient to produce antibodies; and indeed, the rabbit sera contained no antibody to NRS.

Table 3. Time to death of mice immunized with IRS and NRS and challenged with varying doses of Trypanosoma brucei

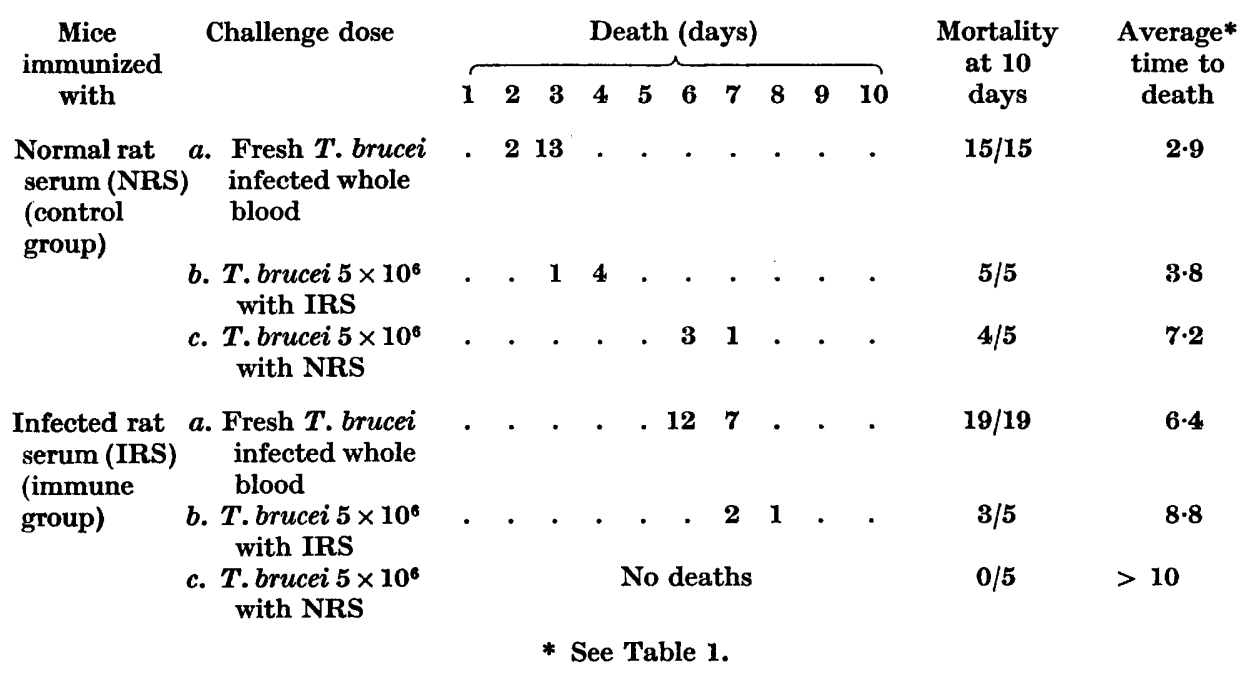

The trypanosomal origin of exoantigen was further demonstrated by the fact that anti-IRS, anti-TH rat sera and anti-TRS rabbit sera agglutinated living suspensions of trypanosomes in vitro. The agglutination is inhibited when the antisera 
are absorbed with IRS but not with NRS. The antibody against exoantigen was therefore at least in part responsible for the agglutination of trypanosomes and the exoantigen is an agglutinogen occurring on the surface of the trypanosomes. The

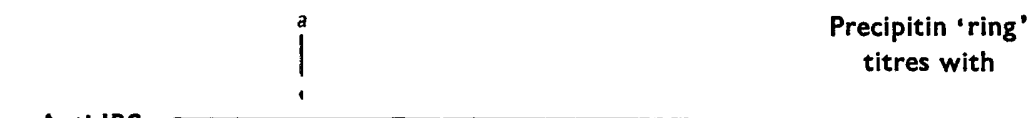

Anti-IRS

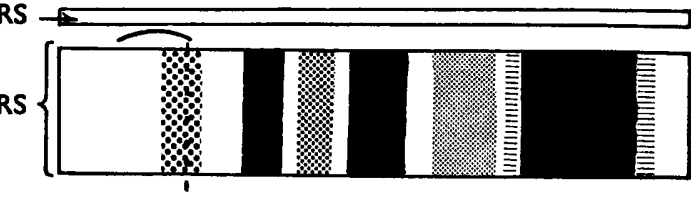

Anti-IRS Anti-NRS

$1 / 320 \quad 1 / 5120$

Anti-TH

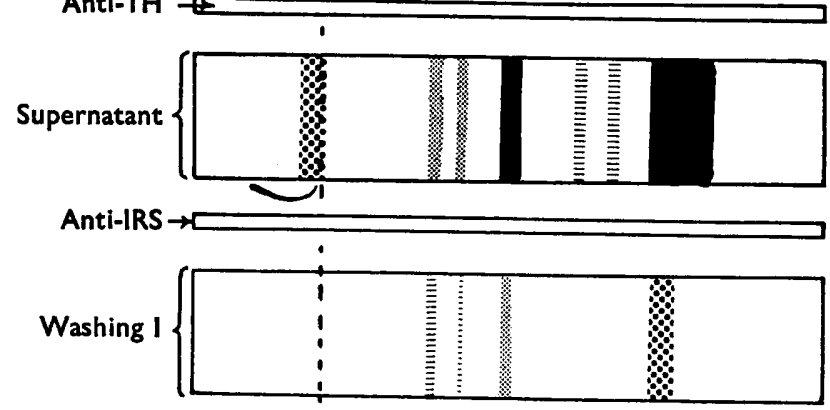

$1 / 160 \quad 1 / 2560$

Anti-TH $\rightarrow \longrightarrow$

$1 / 601 / 1280$

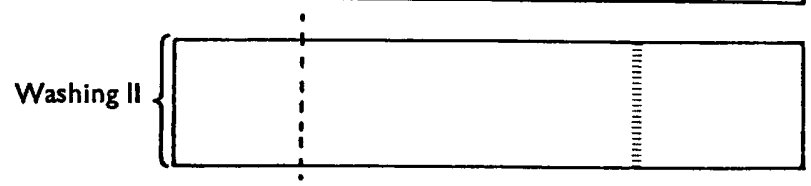

$1 / 40 \quad 1 / 640$

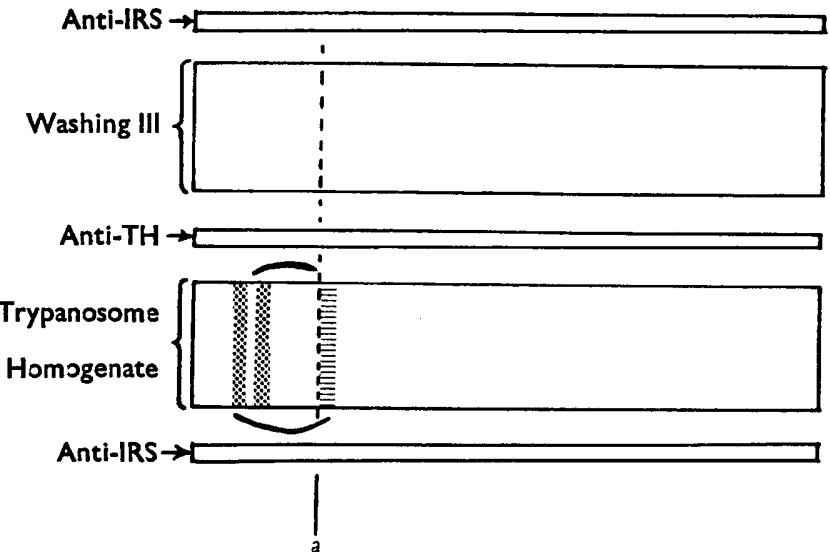

$1 / 40 \quad 1 / 160$

$1 / 2560 \quad 1 / 10$

Fig. 3. Starch gel electrophoresis of the materials in the preparation of trypanosome homogenates and their reactivity with anti-IRS and anti-THS sera. $a, a$ line of insertion of samples.

non-agglutinability of trypanosomes washed in Alsever's solution and presumably free from exoantigen confirms this conclusion.

Immunogenicity of exoantigen. Two groups of mice were given 4-weekly injec- 
tions of $\mathbf{0} \cdot \mathbf{1} \mathrm{ml}$. intraperitoneally of five-times concentrated IRS and NRS respectively. A week after the last injection the mice of both groups were challenged with varying numbers of living trypanosomes to which IRS or NRS was added before inoculation. The time to death of the mice following challenge was longer in all groups of mice injected with IRS compared with those injected with NRS. Table 3 shows the time to death of the two groups of mice challenged with 5 million organisms with IRS and NRS respectively. The severity of the challenge was increased by the addition of IRS as compared with the addition of NRS and the protection of the groups immunized with IRS was related to the severity of the challenge. Thus, mice given the larger number of organisms with IRS added, died earlier than mice given less severe challenge when compared to the group of mice immunized with NRS. Mice immunized with NRS showed no protection at all as compared to normal mice. The mice in both groups which were challenged with $0.1 \mathrm{ml}$. of citrated fresh blood from trypanosome infected rats, being the most severe possible challenge, died very early, while the IRS immunized mice showed a significant protection against this challenge and on average died $3 \frac{1}{2}$ days later than the control group.

\section{The specificity of exoantigen in relation to other trypanosomal antigens}

No component staining with naphthalene black in starch electrophoresis was attributable to exoantigen, but the electrophoretic mobility of exoantigen was indicated by precipitation with anti-IRS rat serum in the corresponding immuno-gel (Fig. 2). In similar conditions disintegrated trypanosomes had two components situated on the negative side of the point of insertion and staining clearly with naphthalene-black (Fig. 3). The antigenicity of these components was established by means of rat antisera to trypanosome homogenates. The ability of trypanosome homogenates to precipitate with such antisera as well as with anti-IRS indicated they also contained exoantigen. However, in gel diffusion tests the lines of precipitation attributed to exoantigen were separate from those attributed to the two homogenate components indicating that exoantigen was distinct from the additional antigens derived from homogenates ('bound antigens'). Figure 3 shows the immunoelectrophoretic patterns of the solutions at various stages of preparation of the homogenates. Supernatant I, derived from the diluted infected blood after centrifugation, has the typical pattern of IRS and reacted with anti-IRS rat serum and anti-NRS serum, but not with anti-TH rat serum. Washing I had a similar but weaker pattern and reactions. Washing II showed no pattern and no lines of precipitation with either antiserum while TH showed only the two lines of the 'bound antigens' reacting with anti-IRS and anti-TH rat serum but not with anti-NRS serum. Thus, after the last washing and before the trypanosomes were disintegrated in the Hughes press, no more exoantigen could be washed off the protozoa, but on breaking them up considerable amounts of antigen were released, showing that relatively large amounts of exoantigens were still present in the cells. 


\section{DISCUSSION}

The presence of soluble and bound antigens of the trypanosomes in infected rats has been established. Whatever the site of synthesis of the exoantigen in the trypanosomes, it is a soluble component occurring on the surface of the organism, whereas the bound antigens are not demonstrable unless the cells are disintegrated. The properties of exoantigen indicate the importance of this component in the process of infection and immunity.

Long ago, Marulli (1910) showed that when the serum of infected guinea pigs was injected at the same time as the infecting trypanosomes (Trypanosoma brucei) intraperitoneally, the infection in guinea pigs developed more rapidly than when the trypanosomes were injected alone. This effect may well have been due to the exoantigen from the infected serum. Exoantigen appears to be essential for the protection of the trypanosome against adverse environmental conditions in vitro and in vivo. Trypanosomes which have been thoroughly washed lose their viability and infectivity. Antibody to exoantigen is lethal to trypanosomes either in vitro or in vivo. This action may reduce them to a state similar to that of well-washed organisms by depriving them of the protective exoantigen. Moreover, the infection of rabbits with trypanosomes results in the formation of antibodies against exoantigen and to a less extent against the 'bound antigens'. The presence of such antibodies in the serum of cattle naturally infected with trypanosomes has already been demonstrated (Gray, 1960).

The agglutination of living trypanosome suspensions (Soltys, 1957) is dependent at least in part on the presence of exoantigen which is regarded as an agglutinogen, the agglutination test merely being a manifestation of one of the properties of the exoantigen. If the species specificity of the agglutination reaction is valid (Soltys, 1957), it is to be expected that the same degree of specificity would apply to the reaction of exoantigen with its antibody. Gray (1960) found antibodies in the serum of cattle naturally infected with Trypanosoma vivax only precipitating homogenates from several species of trypanosomes. The specificity of such cross-reactions in the field, as in laboratory infections, requires a careful study. For this purpose a more sensitive qualitative and quantitative determination of the exoantigen content of IRS based on the inhibition of agglutination of tanned erythrocytes, sensitized with IRS, has been developed. The method was not used in the experimental work described here and will be the subject of a further publication.

Thillet \& Chandler (1957) found with Trypanosoma levisi that suspensions of trypanosomes released soluble 'metabolites' in the suspending medium and that these were immunogenic and agglutinogenic. The preliminary experiments on exoantigen described here had been completed when Thillet \& Chandler reported their findings. It is interesting that much of this work on $T$. brucei agrees with the observations of these authors on $T$. lewisi. To compare the bionomics of $T$. lewisi and $T$. brucei infections in laboratory animals may be confusing considering the function of ablastin in $T$. lewisi infections.

The investigations of the 'bound antigens' are clearly incomplete. Desowitz $(1959 b)$ showed that the homogenates of Trypanosoma rhodesiense had four electrophoretic components; the experiments described here indicate that the exoantigen component would not have been observed under the conditions of his experiments 
and the components he observed could, in fact, be attributed to contamination with rat serum. As none of the components he described was investigated immunologically, it is not possible to make comparisons between the components obtained from the strain of $T$. rhodesiense which he used and the strain of $T$. brucei used in these experiments. The strain and species specificity of the exoantigen and bound antigen require thorough investigation. It is not clear whether the various properties of exoantigen are different manifestations of a single antigenic component or are associated with a number of antigens. The present experimental knowledge suggests that exoantigen of the strain of $\boldsymbol{T}$. brucei used is homogeneous.

Until the protection of mice immunized with exoantigen has been shown effective also against infection with trypanosomes by tsetse fly, the conclusions made here can only apply to infections by syringe inoculation in laboratory animals and the role of soluble antigen in field infection cannot be forecast at present.

\section{REFERENCES}

Desowitz, R. S. (1956). Effect of antibody on the respiratory rate of Trypanosoma vivax. Nature, Lond. 177, 132.

Desowitz, R. S. $(1959 a)$. Studies on immunity and host parasite relationships. I. The immunological response of resistant and susceptible breeds of cattle to trypanosomal challenge. Ann. trop. Med. Parasit. 53, 293.

Desowitz, R. S. (1959b). Paper electrophoresis of trypanosomal extracts. Nature, Lond. 184, 986.

Duke, H. L. \& WALLACE, J. M. (1930). 'Red-cell adhesion' in trypanosomiasis of man and animals. Parasitology, 22, 414.

Fromentin, H. (1959). Trypanosomiase humaine accidentelle à Trypanosoma gambiense. Considérations sur la souche infectante et sur la réponse de l'organisme. Bull. Soc. Path. exot. 52, 181.

Gray, A. R. (1960). Precipitating antibody in trypanosomiasis of cattle and other animals. Nature, Lond. 186, 1058.

Hughes, D. E. (1951). A press for disrupting bacteria and other micro-organisms. Brit. J. exp. Path. 32, 97.

Inoki, S., Kituana, T., Nakabayasi, T. \& Kurogochi, H. (1952). Studies on the immunological variations in Trypanosoma gambiense. Med. J. Osaka University, 3, 357.

KoHN, J. (1959). Small-scale and micro-membrane filter-electrophoresis and immunoelectrophoresis. The Protides of Biological Fluids. Proceedings 6th Colloquium. Bruges, 1958. Amsterdam: Elsevier Publishing Company, 74.

Marulux, A. (1910). Azione esercitata dal siero e dal cavia tripanosomizzata sulla tripanosomiasi sperimentale. Boll. Soc. Ital. Med. Igiene colon. p. 24. Reported in Sleeping Sickness Bur. Bull. 2, 216.

Pantizel, R., Lafaije, A. \& Duret, J. (1959). Diagnostic sérologique de la maladie du sommeil. I. Amélioration de l'antigène préparé à partir de Trypanosoma equiperdum. Bull. Soc. Path. exot. 52, 318.

Polge, C. \& Soltys, M. A. (1957). Preservation of trypanosomes in the frozen state. Trans. R. Soc. trop. Med. Hyg. 51, 519.

Rodhain, J., Valckeg \& van Gidsenhoven, C. (1941). Considérations sur le diagnostic et la thérapeutique de la méningo-encéphalite trypanosomique humaine d'après l'observation de quatre Européens atteints de la maladie du sommeil. Existence dans le sang et le liquide encéphalo-rachidien des malades sensibilisatrices fixant le complément. Ann. Soc. belge Med. trop. 21, 195.

Schochaers, F., Neujean, G. \& Evens, F. (1953). Valeur pratique de la réaction de fixation du complément dans la maladie du sommeil à Trypanosoma gambiense. I. Le diagnostic de la maladie. Ann. Soc. belge Med. trop. 33, 141. 
Smrthies, O. (1955). Zone electrophoresis in starch gels: group variations in the serum proteins of normal human adults. Biochem. J. 61, 629.

Soltys, M. A. (1957). Immunity in trypanosomiasis. II. Agglutination reaction with African trypanosomes. Parasitology, 47, 390.

Thillet, C. J. Jr. \& Chandlen, A. C. (1957). Immunization against Trypanosoma brucei in rats by injections of metabolic products. Science, 125, 346.

Thurston, J. (1958). The effect of immune sera on the respiration of Trypanosoma brucei in vitro. Parasitology, 48, 463.

WALlace, J. M. \& Wormall, A. (1931). Red cell adhesion in trypanosomiasis of man and other animals. II. Some experiments on the mechanism of the reaction. Parasitology, 23, 346.

Wertz, B. (1960). A soluble antigen of Trypanosoma brucei. Nature, Lond. 185, 788. 